\title{
Effect of Misch Metal Nanoparticles on Thermal Decomposition of Ammonia Borane
}

\author{
Aneesh C. Gangal ${ }^{1}$, Raju Edla ${ }^{2}$, Joydev Manna ${ }^{3}$ and Pratibha Sharma ${ }^{4}$ \\ 1,2,3,4 Department of Energy Science and Engineering \\ Indian Institute of Technology Bombay, Mumbai \\ ${ }^{1}$ Gharda Institute of Technology, At Post Lavel, Dist Ratnagiri
}

Correspondence should be addressed to: Aneesh C Gangal; aneeshgangal@gmail.com

Received date: 12 May 2014; Accepted date: 16 June 2014; Published date: 27 May 2015

Academic Editor: Guotao Wu

Copyright (C) 2015. Aneesh C. Gangal, Raju Edla, Joydev Manna and Pratibha Sharma. Distributed under Creative Commons CC-BY 4.0

\begin{abstract}
Ammonia borane $\left(\mathrm{NH}_{3} \mathrm{BH}_{3}\right)$ with its high hydrogen content (19.6\% per mass) and mild desorption conditions has the potential to meet the onboard hydrogen storage requirements for vehicular applications. Ammonia borane decomposes in three steps at the temperatures of about $100^{\circ} \mathrm{C}, 140^{\circ} \mathrm{C}$ and $1000^{\circ} \mathrm{C}$ respectively, releasing one mole equivalent of hydrogen in each step. The major obstacle towards the use of $\mathrm{AB}$ as a hydrogen store is the poor kinetics and irreversibility of the reaction products. With the use of catalyst, the decomposition temperature could be reduced and the kinetics can be improved. In the current work, misch metal (Mm) nanoparticles are used as catalyst. These nanoparticles were synthesized using ball milling and characterized. Homogeneous mixture of $\mathrm{AB}$ and catalyst was prepared in the ratio 10:1 using ball milling. Isothermal as well as non-isothermal studies were performed on neat $A B$ and $A B$ with Mm nanoparticles. Samples as well as solid residues of the decomposition reaction were characterized using XRD and FTIR. It was observed that with catalyst, $A B$ starts releasing hydrogen even at room temperature and the induction period was found to be practically absent. Misch metal is found to be a good catalyst for ammonia borane decomposition.
\end{abstract}

Keywords: Ammonia Borane, Misch metal, Hydrogen Storage, Decomposition

\section{Introduction}

Hydrogen storage is one of the biggest issues associated with the transformation of fossils fuel scenario to hydrogen economy
(Schlapbach \& Züttel, 2001). The available conventional hydrogen storage technologies, i.e. gaseous storage and liquid state storage, have challenges of size, safety and high energy involvement(Manna, Roy, Vashistha,

Cite this Article as : Aneesh C. Gangal, Raju Edla, Joydev Manna and Pratibha Sharma (2015), " Effect of Misch Metal Nanoparticles on Thermal Decomposition of Ammonia Borane ", Journal of Research in Nanotechnology , Vol. 2015 (2015), Article ID 352706, DOI: 10.5171/2015.352706 
\& Sharma, 2013; Zhou, 2005). Hydrogen storage in solid materials, such as sorbents and hydrides, is the safest and effective method(Jain, Jain, \& Jain, 2010; Manna, Vashistha, \& Sharma, 2010; Orimo, Nakamori, Eliseo, Zu, \& Jensen, 2007).Ammonia Borane $(\mathrm{AB})$ is one of the most investigated chemical hydrides due to its enormous hydrogen content (19.6 wt\%) (Gangal, Edla, et al., 2012; Stowe, Shaw, Linehan, Schmid, \& Autrey, 2007). The low decomposition temperature, stability in atmospheric condition, hydrogen release by hydrolysis and thermolysis makes ammonia borane an interesting candidate for hydrogen storage application(U B Demirci, Bernard, Chiriac, Toche, \& Miele, 2011; Umit B Demirci \& Miele, 2010; Rakap \& Ozkar, 2010). It has been reported that the decomposition of ammonia borane occurs in three steps at the temperatures of about $100^{\circ} \mathrm{C}, 140^{\circ} \mathrm{C}$ and above $500^{\circ} \mathrm{C}$, respectively, releasing one mole of hydrogen in each step (Baitalow, Baumann, Wolf, Jaenicke-Rößler, \& Leitner, 2002; Gangal, Kale, Edla, Manna, \& Sharma, 2012). Along with the aforementioned advantages, certain critical issues are also consociated with ammonia borane thermal decomposition, such as, long induction period and slow kinetics of hydrogen evolution, foaming and expansion of the material on heating, release of ammonia and borazine along with hydrogen(Gangal, Edla, et al., 2012).

There are several reports available with addressing and abolishing some of the issues by partially or completely using different heating rates, processes and/or materials(Cheng, Ma, Li, \& Chen, 2007; Gangal, Edla, et al., 2012; Gutowska et al., 2005; He et al., 2009). Wolf et al. analyzed the influence of the heating rate and mentioned that with low heating rates and isothermal conditions, ammonia borane decomposes below its melting point(Wolf, Baumann, Baitalow, \& Hoffmann, 2000). It has been observed that at high pressure, $A B$ decomposes completely in two steps as compared to classical three step decomposition (Nylén et al., 2009). Milling and doping effect on the thermal decomposition of $\mathrm{AB}$ is studied by Benedetto et al. (Benedetto et al., 2006). It has been found that the activation energy of the reaction decreases for doped samples (doping material: hydrogen hexachloroplatinate hydrate) and increases for milled samples. Transition metals, like cobalt and nickel, has catalytic ability on the thermal decomposition of $\mathrm{AB}$ ( $\mathrm{He}$ et al., 2009). Our previous reports showed that, zeolites (Gangal, Edla, et al., 2012) and silicon nanoparticles (Gangal, Kale, et al., 2012) have potential catalytic effect on the ammonia borane thermal decomposition. The current paper deals with misch metal nanoparticles $\left(\mathrm{MmNi}_{4.5} \mathrm{AlO}_{.5}\right)$ as a catalyst and its effect on the thermal decomposition of ammonia borane.

\section{Experimental}

\section{Samples Preparation}

The micron size misch metal with a composition of La 9.17\%, Ce 17.43\%, Pr 1.86\%, Nd 5.34\%, Ni 62.92\%, Al $3.28 \%$ having $\mathrm{LaNi}_{5}$ structure was used as received and was mechanically milled in a FRITSCH Pulverette- 6 ball mill to prepare the nanosized catalyst material. Misch metal was ball milled in the presence of acetone with a speed of $300 \mathrm{rpm}$ for $30 \mathrm{~h}$ in an $80 \mathrm{ml}$ stainless steel (SS) bowl and balls using a FRITSCH Pulverette- 6 machine. The diameter of the SS balls used was $10 \mathrm{~mm}$. The sample to ball ratio was used as $1: 10$. The entire milling cycle consisted of $10 \mathrm{~min}$ milling followed by $10 \mathrm{~min}$ pause to dissipate the generated heat. After ball milling, the bowl was placed inside an inert atmosphere and allowed to evaporate the solvent. The dried powder was then collected and stored in a glove box for further use.

The prepared Mm nanoparticles were mixed with ammonia borane (Sigma-Aldrich) in the $\mathrm{MM}: \mathrm{AB}$ mass ratio of $1: 10$ and were milled for $1 \mathrm{~h}$ to obtain homogenous mixture of $\mathrm{AB}$ and catalyst. The ball to sample ratio was taken as 10:1. All the sample handling was 
done inside a glove box to avoid atmospheric moisture and oxygen. The milled powder of $\mathrm{AB}$ and $\mathrm{Mm}$ will be mentioned as ABMm, throughout the paper.

\section{Characterization and Thermal Decomposition}

The prepared ABMm samples and their decompositions products were characterized by X-ray diffractometry (XRD) using Philips $\mathrm{X}$-ray Diffractometer using $\mathrm{Cu} \mathrm{K} \alpha$ radiation having wavelength $1.54 \AA$ A. The bond connectivity within the samples was observed by Fourier Transform Infrared Spectroscopy (FTIR) using Jasco FTIR system in the range of $400 \mathrm{~cm}^{-1}$ to $4000 \mathrm{~cm}^{-1}$. NonIsothermal decomposition of the sample was studied in a Perkin Elmer TG-DTA system from room temperature to $200{ }^{\circ} \mathrm{C}$ with heating rate of $3{ }^{\circ} \mathrm{C} / \mathrm{min}$. Isothermal decomposition was studied using a standard Sievert's apparatus (Kale, Gangal, Edla, \& Sharma, 2011) at $90,110,135$ and $150^{\circ} \mathrm{C}$. Gas evolved during the isothermal decomposition at $150^{\circ} \mathrm{C}$ was transferred from the reactor to a gas sampler by water displacement method. Subsequently, gas was injected from the sampler into the GC instrument to quantize the gas evolved from the samples.

\section{Results and discussion}

\section{Characterization}

X-ray diffraction pattern of $\mathrm{AB}$ and $\mathrm{ABMm}$, before and after decomposition is compared in the Fig. 1. The sample ABMm shows distinct peaks for ammonia borane as well as $\mathrm{Mm}$, which clearly indicates their uniform distribution and physical mixing during the course of ball milling. The absence of any chemical changes and ionic substitution is also furnished from the obtained X-ray diffraction data. The diffraction pattern of decomposed product of ABMm has only one broad peak in the range $20-30^{\circ}$, which may be formed due to the formation of amorphous product $\left(\mathrm{NH}_{\mathrm{x}} \mathrm{BH}_{\mathrm{x}}\right)$ after heat treatment.

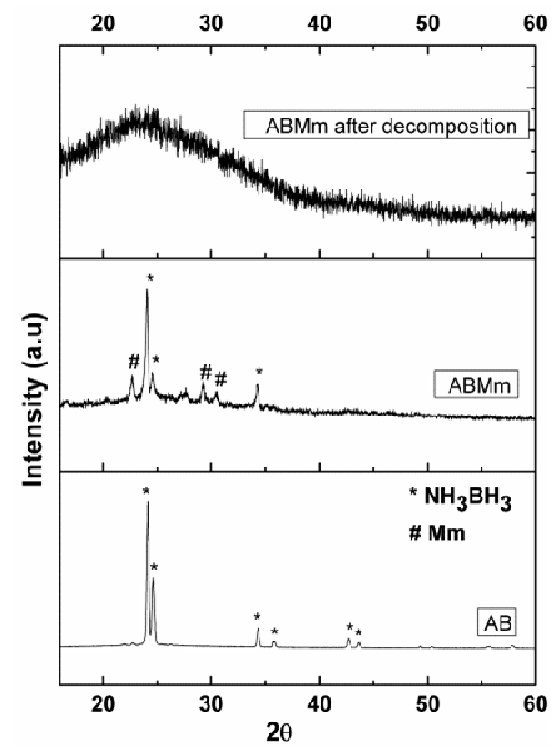

Figure 1: XRD pattern of AB ABMm and ABMmafter decomposition

FTIR spectrum of the ABMm and the decomposed product after heating at different temperature are shown in Fig 2. The spectrum of $A B$ has the characteristic frequency bands corresponding to B-N near $500 \mathrm{~cm}^{-1}, \mathrm{~B}-\mathrm{H}$ in the range of 1000 to 1500 $\mathrm{cm}^{-1}, \mathrm{~N}-\mathrm{H}$ near $1600 \mathrm{~cm}^{-1}$, B-H near $2300 \mathrm{~cm}^{-1}$ and $\mathrm{N}-\mathrm{H}$ near $3300 \mathrm{~cm}^{-1}$ (Gangal, Kale, et al., 
2012; Hu, Geanangel, \& Wendlandt, 1978). As the decomposition temperature increases, $\mathrm{N}$ $\mathrm{H}$ and $\mathrm{B}-\mathrm{H}$ bands are broadened and finally disappear. Disappearance of these two bonds is the prime evidence of hydrogen formation from $A B$ molecules. It can also be seen from the figure that $\mathrm{B}-\mathrm{N}$ band near $500 \mathrm{~cm}^{-1}$ is not disrupted even after decomposition at $150{ }^{\circ} \mathrm{C}$ which rules out the breaking of ammonia borane molecule $\left(\mathrm{H}_{3} \mathrm{~N}-\mathrm{BH}_{3}\right)$ at the middle and therefore there is no possibility of ammonia or diborane gas formation.

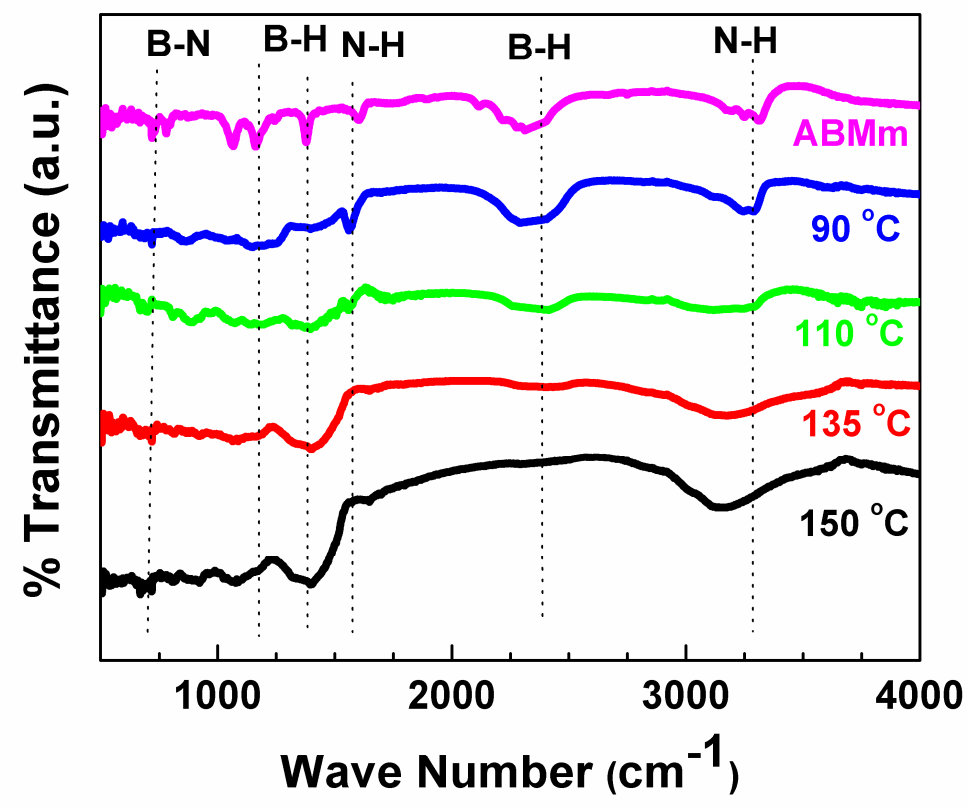

Figure 2: FTIR Spectrum of AB Mm before and after decomposition at different temperature

\section{Thermal Decomposition of $A B$ and $A B M m$}

\section{TG-DTA}

The mass loss and DTA profiles of $\mathrm{AB}$ and ABMm recorded by TG-DTA analyser are shown in Fig 3. Both of the samples were heated upto $300^{\circ} \mathrm{C}$ with a heating rate of $3^{\circ} \mathrm{C} / \mathrm{min}$ in nitrogen atmosphere. For pristine ammonia borane $(\mathrm{AB})$, there is an onset temperature at $108.5^{\circ} \mathrm{C}$ and a second onset is at about $130^{\circ} \mathrm{C}$. Other two humps around 150 and $173.5^{\circ} \mathrm{C}$ are also observed. Around 195$200^{\circ} \mathrm{C}$, mass loss stabilizes at $31.5 \mathrm{wt} \%$. For ABMm sample, mass loss started as soon as heating started. Mass loss can be seen after $50^{\circ} \mathrm{C}$. The melting event for $\mathrm{ABMm}$ sample gets delayed due to the addition of $\mathrm{Mm}$ nanoparticles. The decrease in the exothermicity of the decomposition reaction may be due to the thermal runway after addition of misch metal. On the first event for $\mathrm{ABMm}$, total mass loss is around $3 \mathrm{wt} \%$. Afterwards, gas evolution started around $100^{\circ} \mathrm{C}$ and completed at $250^{\circ} \mathrm{C}$, with a total mass loss of $25.4 \mathrm{wt} \%$. The mass loss during the heating and hydrogen evolution from the samples were closely related. $\mathrm{NH}_{3} \mathrm{BH}_{3}$ contains $19.6 \%$ hydrogen by mass; the excess mass loss may be due to the evolution of other gases, c.a. diborane, ammonia etc. 

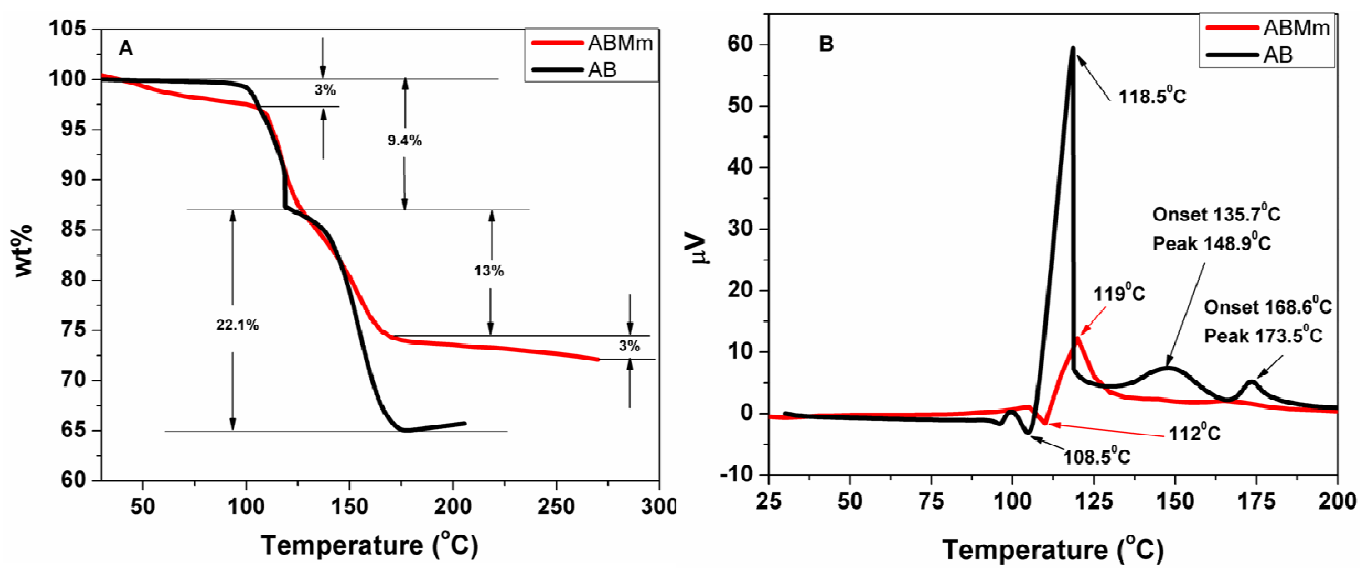

Figure 3: TGA (left) and DTA (right) plots for $A B$ and $A B M m$

\section{Isothermal Decomposition}

Fig $4 \quad(a, b, c, d)$ shows the isothermal decomposition profiles for $\mathrm{AB}$ and $\mathrm{ABMm}$ samples. It has been evident from the figure that at $90^{\circ} \mathrm{C}$, hydrogen evolution is started very fast for $A B M m$ sample than that of $A B$ sample. Absence of induction period is also observed for ABMm sample, which is in well agreement with the obtained TG-DTA result. The amount of hydrogen gas evolved from $\mathrm{AB}$, and $\mathrm{ABMm}$ samples are almost comparable for all the temperature. With the increase in temperature, the amount of hydrogen released increases and the induction period reduces. The amount of gas released in case of isothermal experiments is in the theoretical limits of hydrogen release from $A B$, thus it can be inferred that only hydrogen is released when $\mathrm{AB}$ is decomposed isothermally in a constant volume apparatus. GC of evolved gases of isothermal decomposition reaction on Fig. 5 also confirms the release of only hydrogen and the unwanted gaseous species get suppressed. At 110,135 and $150^{\circ} \mathrm{C}$, hydrogen evolution plots are almost comparable for both samples. The effect of misch metal is not prominent in those cases. This has been occurred possibly due to the destabilization of ammonia borane after its melting at higher temperature. 

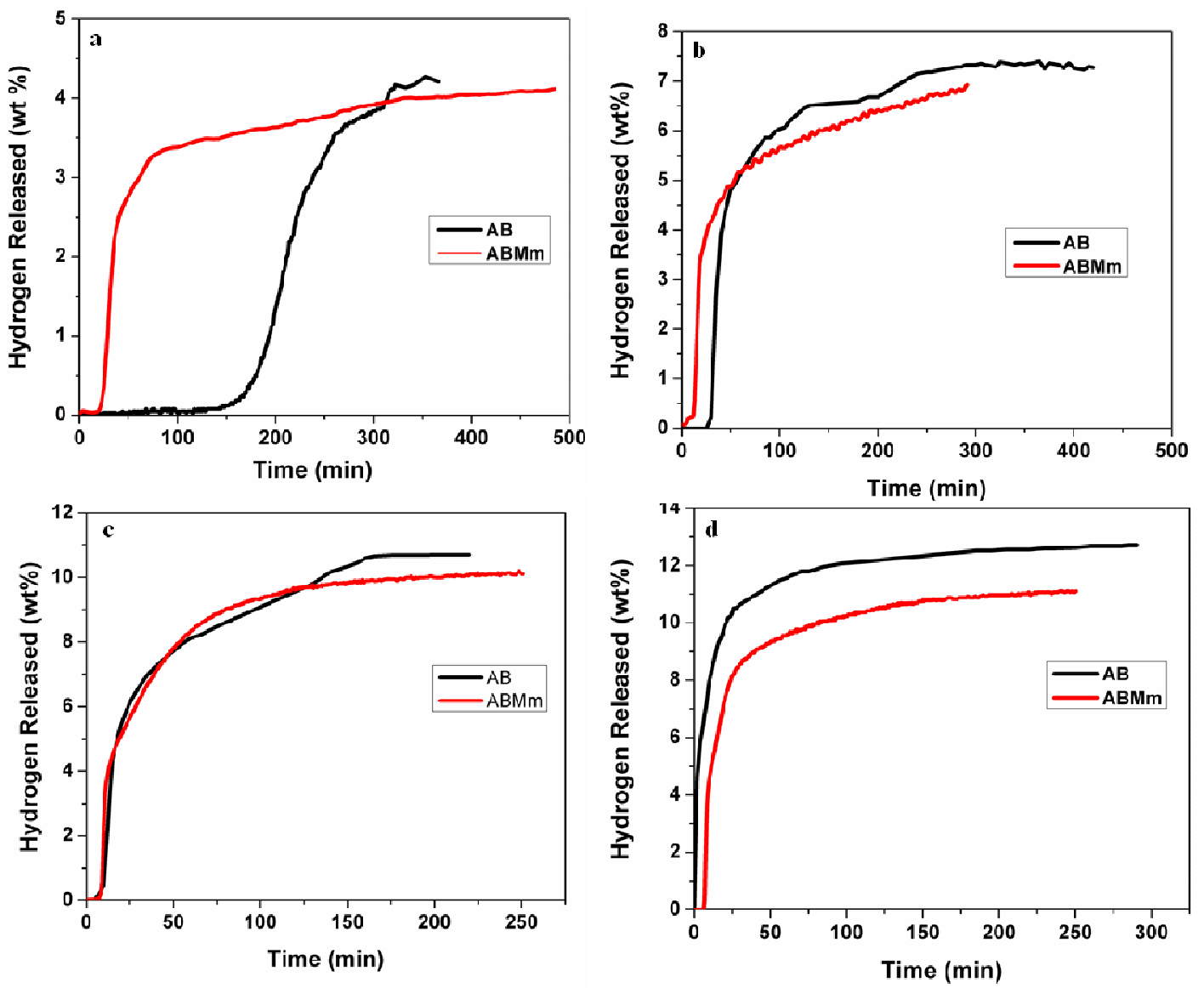

Figure-4 Isothermal decomposition plots of $\mathrm{AB}$ and $\mathrm{ABMm}$ at $(\mathrm{a}) 90^{\circ} \mathrm{C},(\mathrm{b}) 100^{\circ} \mathrm{C}$, (c) $110^{\circ} \mathrm{C}$ and (d) $150^{\circ} \mathrm{C}$

Gas chromatograph was recorded for the gases evolved from decomposition of $\mathrm{AB}$ and ABMm samples after decomposition at $150^{\circ} \mathrm{C}$. Gaseous products were transferred to the GC instrument from Sieverts apparatus using a gas sampler by water displacement method. Fig. 5 shows the gas chromatograph for $\mathrm{ABMm}$ isothermal decomposition at $150^{\circ} \mathrm{C}$. Two peaks can be observed from the figure. The broad and highest peak is attributed to the formed hydrogen gas whereas the small peak appeared due to the air or nitrogen, which was possibly trapped during the gas transfer to the sampler. Thus, it can be inferred that the gas released during the isothermal decomposition is only hydrogen. Similar plots were also obtained for $\mathrm{AB}$ sample. 


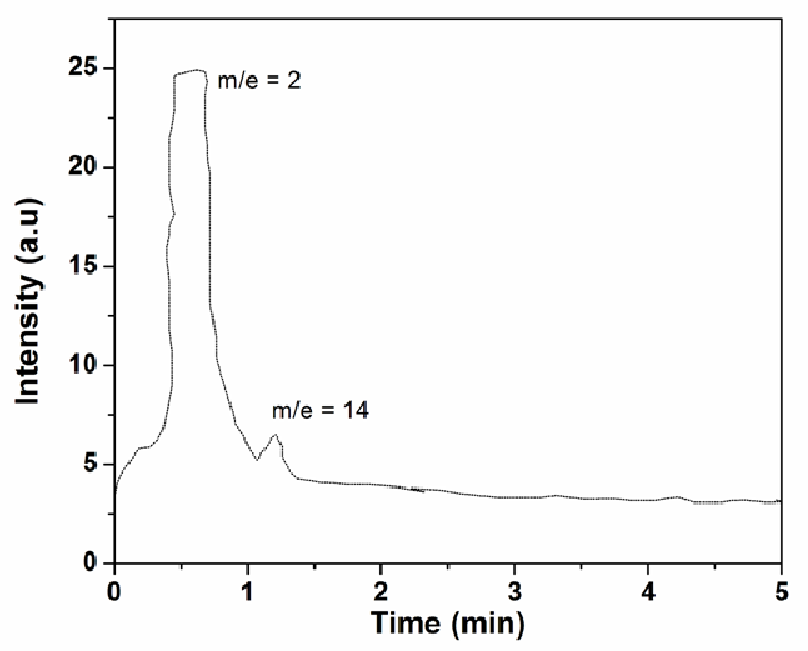

Figure 5 : Chromatograph of gas Evolved of isothermal decomposition of ABMm

\section{Conclusions}

Misch metal nanoparticles are found to be a good catalyst for ammonia borane thermal decomposition by reducing the induction period for $\mathrm{AB}$ decomposition. Reduction in induction period can be attributed to the breaking of the dihydrogen bond and assisting formation of diammoniate of diborane (DADB) Gangal et al., 2012. In the isothermal decomposition of $\mathrm{AB}$ and $\mathrm{ABMm}$, the unwanted gaseous species were suppressed completely and only hydrogen was evolved. The presence of the $\mathrm{B}-\mathrm{N}$ frequencies in the FTIR spectra after decomposition also confirms the formation of pure hydrogen in case of isothermal decomposition.

\section{Acknowledgements}

Authors are thankful to the Ministry of New and Renewable Energy (MNRE), Govt. of India for funding the research work. Authors are also thankful to Dr. I. P. Jain, Rajasthan University for providing catalyst material.

\section{References}

1. Baitalow, F., Baumann, J., Wolf, G., Jaenicke-Rößler, K., \& Leitner, G. (2002). "Thermal decomposition of $\mathrm{B}-\mathrm{N}-\mathrm{H}$ compounds investigated by using combined thermoanalytical methods" Thermochimica Acta, 391(1-2), 159-168.

2. Benedetto, S. De, Carewska, M., Cento, C., Gislon, P., Pasquali, M., Scaccia, S., \& Prosini, P. P. (2006). "Effect of milling and doping on decomposition of NH3BH3 complex" Thermochimica Acta, 441(2), 184-190.

3. Cheng, F., Ma, H., Li, Y., \& Chen, J. (2007). Ni1-xPtx (x $0-0.12)$ "Hollow Spheres as Catalysts for Hydrogen generation from ammonia borane" Inorganic Chemistry, 46, 788-794.

4. Demirci, U. B., Bernard, S., Chiriac, R., Toche, F., \& Miele, P. (2011). "Hydrogen release by thermolysis of ammonia borane NH3BH3 and then hydrolysis of its byproduct [BNHx]". Journal of Power Sources, 196(1), 279-286. 
5. Demirci, U. B., \& Miele, P. (2010). "Hydrolysis of solid ammonia borane". Journal of Power Sources, 195(13), 40304035.

6. Gangal, A. C., Edla, R., Iyer, K., Biniwale, R., Vashistha, M., \& Sharma, P. (2012). "Effect of zeolites on thermal decomposition of ammonia borane" International Journal of Hydrogen Energy, 37(4), 3712-3718.

7. Gangal, A. C., Kale, P., Edla, R., Manna, J., \& Sharma, P. (2012). "Study of kinetics and thermal decomposition of ammonia borane in presence of silicon nanoparticles" International Journal of Hydrogen Energy, 37(8), 6741-6748.

8. Gutowska, A., Li, L., Shin, Y., Wang, C. M., Li, X. S., Linehan, J. C., Autrey, T. (2005). "Nanoscaffold mediates hydrogen release and the reactivity of ammonia borane" Angewandte Chemie (Int Ed.), 44, 3578-82.

9. He, T., Xiong, Z., Wu, G., Chu, H., Wu, C., Zhang, T., \& Chen, P. (2009). "Nanosized Coand Ni-Catalyzed Ammonia Borane for Hydrogen Storage" Chemistry of Materials, 21(11), 2315-2318.

10. Hu, M. G., Geanangel, R. A., \& Wendlandt, W. W. (1978). "The thermal decomposition of ammonia borane" Thermochimica Acta, 23, 249-255.

11. Jain, I. P., Jain, P., \& Jain, A. (2010). “Novel hydrogen storage materials: A review of lightweight complex hydrides" Journal of Alloys and Compounds, 503(2), 303-339.

12. Kale, P., Gangal, A. C., Edla, R., \& Sharma, P. (2011). "Investigation of hydrogen storage behavior of silicon nanoparticles" International Journal of Hydrogen Energy, 37(4), 3741-3747.

13. Manna, J., Roy, B., Vashistha, M., \& Sharma, P. (2013). "Effect of Co+2/BH4ratio in the synthesis of Co-B catalysts on sodium borohydride hydrolysis"
International Journal of Hydrogen Energy, 39 (1), 406-413

14. Manna, J., Vashistha, M., \& Sharma, P. (2010). "Lithium Borohydride as a Hydrogen Storage Material: A Review". International Journal of Energy for a Clean Environment, 11(1-4).

15. Nylén, J., Sato, T., Soignard, E., Yarger, J. L., Stoyanov, E., \& Häussermann, U. (2009). "Thermal decomposition of ammonia borane at high pressures" The Journal of Chemical Physics, 131(10),

16. Orimo, S., Nakamori, Y., Eliseo, J. R., Zu, A., \& Jensen, C. M. (2007). "Complex Hydrides for Hydrogen Storage" Chemical Review, 107, 4111-4132.

17. Rakap, M., \& Ozkar, S. (2010). "Zeolite confined palladium ( 0 ) nanoclusters as effective and reusable catalyst for hydrogen generation from the hydrolysis of ammoniaborane". International Journal of Hydrogen Energy, 35, 1305-1312.

18. Schlapbach, L., \& Züttel, A. (2001). "Hydrogen storage materials for mobile applications” Nature, 414, 353-358.

19. Stowe, A. C., Shaw, W. J., Linehan, J. C., Schmid, B., \& Autrey, T. (2007). "In situ solid state 11B MAS-NMR studies of the thermal decomposition of ammonia borane: mechanistic studies of the hydrogen release pathways from a solid state hydrogen storage material" Physical Chemistry Chemical Physics, 9(15), 1831-6.

20. Wolf, G., Baumann, J., Baitalow, F., \& Hoffmann, F. P. (2000). "Calorimetric process monitoring of thermal decomposition" Thermochimica Acta, 343, 19-25.

21. Zhou, L. (2005). "Progress and problems in hydrogen storage methods" Renewable and Sustainable Energy Reviews, 9(4), 395408. 